\title{
nature
}

1 November 2001 Volume 414 Issue no 6859

\section{Finding a future for GM crops}

Some parties to debates over the safety of genetically modified crops don't want to hear the results of objective research. But that isn't an excuse for not doing it.

$\mathrm{O}$ all of the tactics employed by the opponents of genetically modified (GM) crops in Europe, one of the most effective has been to publicize the connections between private companies selling agricultural biotechnology and the scientists assessing the safety of the crops.

For those unfamiliar with how research is funded, this information can create the impression of a conflict of interest. Many of the scientists involved serve as advisers to the companies. Others carry out research funded by the firms. These links need not undermine the integrity of anybody's research, but they have nonetheless undermined public confidence in that integrity.

Governments seem unperturbed by the damage caused by this impression. In Britain, for example, an industry-funded body, the Supply Chain Initiative on Modified Agricultural Crops, has helped to coordinate farm-scale trials of the crops' impact on biodiversity. Industry has a similar role in trials elsewhere in Europe. In the United States, where the crops are already grown in large quantities, federal agencies have been happy to let the industry itself carry out most of the research into the safety and environmental impact of GM crops.

There's nothing intrinsically wrong with involving industry in such pre-regulatory research. Those doing the research gain from the considerable expertise of the corporations that have developed the transgenic crop strains, and the taxpayer benefits from having industry foot the bill. But the arrangement can undoubtedly provide ammunition for those who later attempt to discredit the studies. And if industry's role in the work is predominant, this criticism may have a point.

This September, for example, the Agriculture and Environment Biotechnology Commission (AEBC), an independent body advising the British government, reported that the range of indicators of biodiversity that are being used in the UK farm-scale trials is too narrow to assess the crops' impact properly.

The AEBC didn't attack the impartiality of the scientists involved or the quality of their work. There was no reason to do so: if the work is carried out at independent research institutes and is properly peer reviewed, there is no reason why industry's funding should bias its results. The problem lies not in the individual projects, but rather in the range of questions they address. If the agricultural biotechnology industry sets the questions - as appears to have happened in this case - then the research is unlikely to fulfil the public's interest.

The British government needn't look too far to fix this problem. Its own Food Standards Agency (FSA) has a similar remit to the AEBC's in terms of providing strategic advice. But it also has a modest research budget of its own, $\mathfrak{£} 21$ million (US\$30 million) a year, so that it can commission the research it deems necessary. The government should consider expanding the AEBC's remit along similar lines, initially, perhaps, giving it a mandate to draw up a framework for the GM-crop-related research that is required in the United Kingdom.

In the United States, regulation of GM crops is divided between three agencies — the Food and Drug Administration, the Environmental Protection Agency and the US Department of Agriculture depending on the genetic modification to the crop. But all three agencies are severely constrained in their ability to set a research agenda that will protect the public interest. Funding for research on GM technology is too heavily concentrated in the hands of producers to be compatible with that objective.

The wide acceptance of GM crops in the United States, and their likely rejection in Europe regardless of what the studies say, might suggest that reforming research to give better information is an academic exercise. But it is still worth doing. The results of past and future trials will feed into the looming trade dispute over whether European rules on issues such as labelling of crops are protectionist. And new GM crops will have to be assessed as the technology advances. If the research agenda is to help governments meet these challenges, it must be set independently of industrial influence, and seen as such.

\section{Double standards}

Developing countries deserve as much leeway to deal with their public-health crises as the United States has allowed itself.

T he next ministerial meeting of the World Trade Organization in Doha, Qatar, on 9-13 November promises to be a lively affair. One agenda item, in particular, that will demand attention is an expected appeal by developing nations, led by Brazil, for greater leeway in the compulsory licensing of pharmaceuticals in the event of public-health emergencies, under the TRIPS (Trade-Related Intellectual Property Rights) agreement.

Brazil, the advocacy group Doctors Without Borders and many African governments have for some time been pushing for greater use of a provision in TRIPS that allows nations to override patent protection on drugs in "national emergencies". The US government has opposed this flexibility, sometimes threatening to challenge the use of the provision by developing countries facing AIDS crises.

It is salutary, then, to see how America has responded to a national emergency of its own — the recent anthrax attacks — that required action on drug affordability. Initially, Canada announced that it would license the production of Cipro (ciprofloxacin), a treatment for anthrax, by suppliers other than the drug's patent holder, Bayer. Then Senator Chuck Schumer (Democrat, New York) began to appear on television demanding that the United States do the same.

The Bush administration at first dismissed such action as illegal. But, forced by the persistent senator to acknowledge that this was not the case, it proceeded to extract agreement from Bayer to supply the drug at about one-fifth of its previous price. The health secretary, Tommy Thompson, even boasted that the threat of compulsory licensing had helped to clinch the deal.

No such muscle is available to the smaller African nations, whose populations are being ravaged by AIDS. They should demand as much leeway in interpreting TRIPS as the United States has seen fit to allow itself. 